\title{
Association of vitamin D deficiency with occurrence of pre eclampsia among inpatients of tertiary care centre, Gorakhpur, Uttar Pradesh, India
}

\author{
Aradhana Singh*, Sweta Mishra, Vani Aditya, Reena Srivastava
}

Department of Obstetrics and Gynaecology, B.R.D Medical College, Gorakhpur, Uttar Pradesh, India

Received: 14 April 2016

Accepted: 19 April 2016

\section{*Correspondence:}

Dr. Aradhana Singh,

E-mail: aradhanamdobg@gmail.com

Copyright: (C) the author(s), publisher and licensee Medip Academy. This is an open-access article distributed under the terms of the Creative Commons Attribution Non-Commercial License, which permits unrestricted non-commercial use, distribution, and reproduction in any medium, provided the original work is properly cited.

\begin{abstract}
Background: Pre eclampsia has remained a significant public health threat in both developed and developing countries contributing to maternal and perinatal morbidity and mortality globally. Vitamin D has direct influence on molecular pathways proposed to be important in the pathogenesis of pre eclampsia, yet the vitamin D-pre eclampsia relation has seldom been studied. In the present study we aimed to assess the association of vitamin D deficiency with the occurrence of pre eclampsia. If indeed vitamin D deficiency is related to pre eclampsia, this correlation can inform future studies, which hopefully will ultimately lead to a decrease in the incidence of pre eclampsia hence a decrease in adverse maternal and fetal outcomes.

Methods: We conducted a comparative cross sectional study carried out for a period of one year from August 2014 to July 2015. A total of 384 patients were selected. 192 pre eclamptic and 192 non pre eclamptic pregnant patients aged 16-45 years attending in-patient department of Obstetrics and Gynaecology BRD Medical college Gorakhpur were included in the study.

Results: About $82.8 \%$ of pre eclamptic and $31.25 \%$ of non pre eclamptic patients were found deficient in vitamin D. Also, severe pre eclamptic patients had more severe deficiency of vitamin D. Majority of these patients (51.78\%) had very low vitamin $\mathrm{D}$ concentration.

Conclusions: Maternal vitamin D deficiency may be an independent risk factor for preeclampsia. Vitamin D supplementation in pregnancy should be explored for preventing preeclampsia and promoting neonatal well-being.
\end{abstract}

Keywords: Pre eclampsia, Vitamin D, Patients

\section{INTRODUCTION}

Pre eclampsia is associated with an enhanced burden of severe obstetric morbidity. Worldwide, the incidence of preeclampsia ranges between $2 \%$ and $10 \%$ of pregnancies. WHO estimates the incidence of preeclampsia to be seven times higher in developing countries $(2.8 \%$ of live births) than in developed countries $(0.4 \%){ }^{1}$ various risk factors and preventive measures for pre eclampsia have been tested, still there are no definitive preventive measures.
The current hypothesis regarding the aetiology of preeclampsia is focused on mal adaptation of immune responses and defective trophoblastic invasion. Thus, an excessive maternal inflammatory response, perhaps directed against foreign foetal antigens, results in a chain of events including shallow trophoblastic invasion, defective spiral artery remodelling, placental infarction and release of pro-inflammatory cytokines and placental fragments in the systemic circulation. ${ }^{2}$ Maternal immune rejection of the placental cytotrophoblastic invasion of spiral arteries leads to shallow implantation and hypoxia 
and release of inflammatory mediators. With the recognition of immune modulator properties of vitamin D it has been the subject of recent research. Vitamin D receptors and 1- $\alpha$ hydroxylase are expressed both in decidua and trophoblastic cells. ${ }^{3,4}$ providing an evidence for role of vitamin D in placentation. Evidence also exist that vitamin $\mathrm{D}$ is able to regulate key target genes associated with implantation of the embryo, trophoblastic invasion and implantation tolerance. ${ }^{3}$

High incidence of vitamin D deficiency in early pregnancy is found in a tropical country like India which has abundant sunlight for most of the year. This paradox can be explained due to many prevalent social and cultural practices i.e. increased urbanization, poor outdoor activity, greater pollution that preclude exposure of women to sunlight coupled with skin pigment melanin which absorbs ultraviolet $\mathrm{B}$ photons and reduces vitamin D synthesis by greater than $90 \%$. Since pre eclampsia contributes to $9 \%$ of maternal deaths in Asia ${ }^{5}$ finding relation with vitamin $\mathrm{D}$ may lead us to a non-expensive measure to possibly prevent it. This would have widespread maternal health implication, as so far we do not have definitive preventive measures. So this study was conducted to study the association of vitamin D deficiency with pre eclampsia.

\section{METHODS}

We conducted a quantitative cross sectional study for a period of one year from August 2014 to July 2015. Patients who were included in this study had to provide consent for the collection of demographic and outcome data and venipuncture for collection of plasma to be used in 25-OH-D analysis. Cases were recruited from the inpatient Labour and Delivery unit at the Obstetrics and Gynaecology department BRD Medical College Gorakhpur, after confirmation of the diagnosis of pre eclampsia. Equal numbers of normotensive pregnant females were also taken. Pre eclamptic cases had to meet the American College of Obstetrics and Gynaecology criteria for diagnosing pre eclampsia. Patients with chronic hypertension, gestational diabetes mellitus, renal disease, liver disease, autoimmune disorders, or multi fetal gestation were excluded. A total of 384 admitted pregnant women were enrolled which were further categorized into two equal, pre eclamptic and non pre eclamptic groups. Detailed data were collected via inperson interviews. Pre-designed and pre-tested questionnaires administered to the targeted participants and information was collected. The demographic age was self-reported, and was recorded as a whole number in years at the time of screening. Age was then classified into the following four categories: <20 years, 21-30 years, 31-40 years and >40 years. Religion was selfreported. It was categorized into the following groups Hindus, Muslims and others. Parity, family history preexisting medical conditions, gestational age, education, socioeconomic status, prenatal vitamin D use, smoking status, intake of Vitamin D rich products and sun exposure habits were enquired. Fasting blood samples were drawn from the enrolled patients. Vitamin D concentration was determined by the concentration of 25$\mathrm{OH}$ vitamin $\mathrm{D}$ in $\mathrm{ng} / \mathrm{ml}$ (normal range 20 to $100 \mathrm{ng} / \mathrm{ml}^{6-8}$ ) in the serum of participants. $25-\mathrm{OH}$ vitamin $\mathrm{D}$ concentration of $<20 \mathrm{ng} / \mathrm{ml}$ was considered as deficient, while concentrations of $\geq 20 \mathrm{ng} / \mathrm{ml}$ and above was considered as sufficient.

\section{Measurement of vitamin D}

Venipuncture was used to collect fasting blood samples. Quantitation of serum $25(\mathrm{OH})$ vitamin D $\left(25(\mathrm{OH}) \mathrm{D}_{2}\right.$ plus $25(\mathrm{OH}) \mathrm{D}_{3}$ ) was performed using a commercial ELISA from Immunodiagnostic Systems Limited in the Pathology laboratory of BRDMC. The ELISA could detect $25(\mathrm{OH})$ vitamin $\mathrm{D}$ in the range of $2-120 \mathrm{ng} / \mathrm{ml}$. This assay can detect $25(\mathrm{OH}) \mathrm{D}_{3}$ conc. as low as 1.28 $\mathrm{ng} / \mathrm{ml}$. None of the samples in our analysis fell below the detectable range. The inter assay coefficient of variation for the ELISA was $10.3 \%$. The ELISA recognized $100 \%$ of $25(\mathrm{OH})$ vitamin $\mathrm{D}_{3}$ and $75 \%$ of $25(\mathrm{OH})$ vitamin $\mathrm{D}_{2}$ but did not distinguish between these two forms.

Because there is no universally acceptable definition of vitamin D deficiency, we used cut off points suggested recently by some studies. ${ }^{23,24,26}$ Serum samples were drawn at similar gestational ages in both the groups.

Statistical analyses were performed and data summarized using basic descriptive statistics. We performed the unadjusted analyses chi square tests to compare and observe differences between pre eclamptic and non pre eclamptic groups. All $\mathrm{P}$ values were two-tailed, with $\mathrm{P}<0.05$ considered statistically significant.

\section{RESULTS}

All the selected patients were matched in terms of age, parity, religion, gestational age, socioeconomic status, and education i.e. the number of patients falling in both the groups was almost the same.

Majority of the patients in both pre eclamptic (82.29\%) and non pre eclamptic groups $(66.14 \%)$ were not taking vitamin D supplements. Among pre eclamptic only $36.45 \%$ patients were exposed to sunlight for $>1 / 2$ hours a day. Rest of them (63.5\%) receive sunlight for $<1 / 2$ hours a day. Among non pre eclamptic $56.25 \%$ were exposed for $>1 / 2$ hours and only $43.75 \%$ for $<1 / 2$ hours (Table 1).

About $82.8 \%$ of pre eclamptic and $31.25 \%$ of non pre eclamptic patients were found deficient in vitamin D. Vitamin D levels were sufficient in $17.2 \%$ of pre eclamptic and $68.75 \%$ of non pre eclamptic patients (Table 2) 
Table 1: Demographic characteristics.

\begin{tabular}{|c|c|c|}
\hline Maternal characteristics & $\begin{array}{l}\text { Pre } \\
\text { eclamptic } \\
(\%)\end{array}$ & $\begin{array}{l}\text { Non pre } \\
\text { eclamptic } \\
(\%)\end{array}$ \\
\hline \multicolumn{3}{|l|}{ Age (years) } \\
\hline$<20$ & 5.73 & 1.04 \\
\hline $20-30$ & 54.17 & 58.85 \\
\hline $30-40$ & 32.29 & 29.16 \\
\hline$>40$ & 7.81 & 10.93 \\
\hline \multicolumn{3}{|l|}{ Religion } \\
\hline Hindu & 53.64 & 58.33 \\
\hline Muslims & 46.35 & 41.66 \\
\hline Others & 0 & 0 \\
\hline \multicolumn{3}{|l|}{ Rural/urban } \\
\hline Rural & 70.83 & 56.25 \\
\hline Urban & 29.16 & 43.75 \\
\hline \multicolumn{3}{|l|}{ Education } \\
\hline Illiterate & 40.63 & 41.14 \\
\hline Primary & 34.89 & 34.89 \\
\hline Secondary & 19.79 & 23.96 \\
\hline Higher & 4.68 & 0 \\
\hline \multicolumn{3}{|l|}{ Socioeconomic } \\
\hline Class 1 & 1.04 & 1.56 \\
\hline Class 2 & 40.1 & 30.72 \\
\hline Class 3 & 35.41 & 46.33 \\
\hline Class 4 & 16.67 & 15.62 \\
\hline Class 5 & 7.82 & 5.72 \\
\hline \multicolumn{3}{|l|}{ Smoking } \\
\hline Yes & 1.04 & 1.56 \\
\hline No & 98.95 & 98.43 \\
\hline \multicolumn{3}{|l|}{ Gravidity } \\
\hline Primi & 51.56 & 46.87 \\
\hline 2 & 10.93 & 16.14 \\
\hline 3 & 21.87 & 23.44 \\
\hline$>/=4$ & 15.62 & 13.54 \\
\hline \multicolumn{3}{|c|}{ Use of vitamin D supplements } \\
\hline Yes & 17.71 & 33.85 \\
\hline No & 82.29 & 66.14 \\
\hline \multicolumn{3}{|l|}{ Sun exposure } \\
\hline Adequate & 36.45 & 56.25 \\
\hline Inadequate & 63.5 & 43.75 \\
\hline
\end{tabular}

Table 2: Vitamin D status.

\begin{tabular}{|lllll|}
\hline $\begin{array}{l}\text { Vitamin D } \\
\text { levels }\end{array}$ & \multicolumn{2}{l}{$\begin{array}{l}\text { Pre eclamptic } \\
(\mathbf{n = 1 9 2})\end{array}$} & $\begin{array}{l}\text { Non pre eclamptic } \\
(\mathrm{n}=192)\end{array}$ \\
\cline { 2 - 5 } & No. & $\%$ & No. & $\%$ \\
\hline Deficient & 159 & 82.8 & 60 & 31.25 \\
\hline Not deficient & 33 & 17.2 & 132 & 68.75 \\
\hline
\end{tabular}

Majority of primi gravida patients in both the groups were deficient in vitamin D. It was also found that majority of severe pre eclamptic patients $(51.78 \%)$ had very low (<10 ng/ml) vitamin D concentration (Table 3$)$.

Table 3: relationship of severity of pre eclampsia with vitamin D levels.

\begin{tabular}{|lllll|}
\hline $\begin{array}{l}\text { Vitamin D } \\
\text { levels }\end{array}$ & \multicolumn{2}{c|}{ Mild pre eclampsia } & \multicolumn{2}{l|}{$\begin{array}{l}\text { Severe pre } \\
\text { eclampsia }\end{array}$} \\
\hline$(\mathrm{ng} / \mathrm{ml})$ & No. & $\%$ & No. & $\%$ \\
\hline$<10$ & 12 & 8.82 & 29 & 51.78 \\
\hline $10-20$ & 76 & 55.88 & 15 & 26.78 \\
\hline $20-100$ & 48 & 35.29 & 12 & 21.43 \\
\hline$>100$ & 00 & 00 & 00 & 00 \\
\hline Total & 136 & 100 & 56 & 100 \\
\hline
\end{tabular}

\section{DISCUSSION}

Factors that play a role in the pathogenesis of pre eclampsia have not yet been fully determined. Many hypotheses have been suggested through clinical testing. Studies conducted on this subject point out the role of deficient vitamin D levels in pre eclampsia through increasing inflammation and all such studies are compatible with the anti-inflammatory role of vitamin D. ${ }^{7}$ Consistent with previous studies, this study also found lower maternal $25 \mathrm{OH}$ vitamin $\mathrm{D}$ serum levels in pre eclamptic than in non pre eclamptic patients. This is comparable to a nested case control study by Bodnar et al. ${ }^{8}$ 25-hydroxyvitamin $\mathrm{D}$ was measured in banked serum. The 25 hydroxy vitamin D concentrations in early pregnancy were significantly lower in 55 women who developed pre eclampsia later in pregnancy than in 219 women who did not develop pre eclampsia.

There are other studies with similar results. ${ }^{9-15}$ Almost similar study done by Robinson in 2010 in which patients with early onset severe pre eclampsia had significantly decreased ( $p$ value $<0.001$ ) levels of $25-\mathrm{OH}-\mathrm{D}$ relative to healthy control pregnancies. ${ }^{15}$

However, some studies have not supported the association between vitamin D and pre eclampsia. Shand and Nassar reported no significant association between adverse pregnancy outcomes and serum 25OHD concentration levels. ${ }^{16}$

Levels of total and free $25(\mathrm{OH})$ vitamin $\mathrm{D}$ in first trimester was not found to be associated with either first trimester blood pressure or development of subsequent pre eclampsia in a study done by Powe et al. ${ }^{17}$ Also Wetta et al., in their case control study, demonstrated that serum $25(\mathrm{OH})$ vitamin $\mathrm{D}$ levels measured at the $15^{\text {th }}$ and $21^{\text {st }}$ week of pregnancy, in the two groups were similar. ${ }^{18} \mathrm{~A}$ meta-analysis done to assess the association between maternal serum vitamin D levels and risk of pre eclampsia included 15 articles and 8 studies. They concluded that the overall effect was significant for studies that defined vitamin $\mathrm{D}$ deficiency as $25(\mathrm{OH})$ $\mathrm{D} \leq 50 \mathrm{nmol} / \mathrm{L}(20 \mathrm{ng} / \mathrm{ml})$, but not for those which considered it as $<38 \mathrm{nmol} / \mathrm{L}(15.2 \mathrm{ng} / \mathrm{ml}){ }^{19}$ 
In a relatively large prospective study performed in Norway by Haugen et al., the risk of pre eclampsia was found to be decreased by $27 \%$ in patients who received vitamin $\mathrm{D}$ in a dose of 400-600 IU/ daily through supplemental treatment. ${ }^{20}$ However in a Randomised Controlled Trial conducted by Marya et al., no significant difference was found in the incidence of preeclampsia between cases with or without vitamin $D$ supplementation (1,200 IU/daily) during the $20^{\text {th }}$ and $24^{\text {th }}$ week of pregnancy in 400 patients. $^{21}$

In the present study among pre eclamptic patients most $(63.5 \%)$ were inadequately exposed to sunlight as compared to non pre eclamptic patients among whom $43.75 \%$ received inadequate exposure. This is comparable to a study done by Magnus and Eskild where mothers of children born in summer had the lowest risk of pre eclampsia, and the risk was highest in the winter months. ${ }^{22}$ In the present study vitamin D deficiency was found in majority of patients $(82.8 \%)$ with pre eclampsia, suggesting that maternal $25(\mathrm{OH})$ vitamin D deficiency in pregnancy is associated with an increased risk of pre eclampsia. This is similar to study done by Baker et al who found that mid gestation maternal $25(\mathrm{OH})$ vitamin $\mathrm{D}$ concentration was lower in women who subsequently developed severe preeclampsia compared with controls. ${ }^{23}$ In a case-cohort study it was found that maternal vitamin D deficiency may be a risk factor for severe pre eclampsia, but it is not associated with pre eclampsia overall or its mild subtypes. $^{9}$

No significant difference was found in vitamin D status among both mild and severe subtypes of pre eclampsia. Overall the level of supplementation was very low, in both the groups probably because of high level of illiteracy and maximum number of patient belonging to lower socioeconomic class.

Regarding sun exposure habits it was found that most of the pre eclamptic patients were inadequately exposed to sunlight.

In light of previous findings of a positive association between low vitamin D status and pre eclampsia and the biological plausibility of the association. This finding needs to be tested in a larger sample size. In addition studies focusing on women in eastern U.P. alone should be carried out to determine the true nature of the association between low vitamin D status and disparity of pre eclampsia rates in this population. Such an approach would diffuse the effects to a vastly heterogeneous population.

\section{ACKNOWLEDGEMENTS}

We are very thankful to Dr. Rajiv Mishra Professor and Head of Department (Pathology) for assisting us in getting the investigations done free of cost, without which this study could not have been possible.
We thankfully acknowledge the support provided by Dr. Harish Chandra Tiwari (Lecturer, Department of Community Medicine) for statistical assistance.

Funding: No funding sources

Conflict of interest: None declared

Ethical approval: The study was approved by the Institutional Ethics Committee

\section{REFERENCES}

1. Osungbade KO, Olusimbo K LGE. Public health perspectives of pre eclampsia in developing countries: implications for health system strengthening. J Pregnancy. 2011(2011);1-6.

2. Matthiesen L, Berg G. Ernerudh J, Ekerfelt C, Jonsson Y, Sharma S. Immunology of Pregnancy. Chem Immunol Allergy. 2005;89:49-61.

3. Evans KN, Bulmer JN, Kilby MD, Hewison M. Vitamin D and placental-decidual function. J Soc Gynecol Investig. 2004;11(5):263-71.

4. Zhender D, Bland R, Williams MC, McNinch RW, Howie AJ, Stewart PM et al. Extra renal expression of 25-hydroxyvitamin d(3)-1 alpha-hydroxylase. J Endocrinol Metab. 2001;86(2):888-94.

5. Khan KS, Wojdyla D, Say L, Gülmezoglu AM, Van Look PFA. WHO analysis of causes of maternal death: a systematic review. Lancet. 2006;367:106674.

6. Hollis BW. Circulating 25-hydroxy vitamin D levels indicative of vitamin D sufficiency: implications for establishing a new effective dietary intake recommendation for vitamin D. J Nutr. 2005;135:317-22.

7. Holmes VA, Barnes MS, Alexander HD, McFaul P, Wallace JMW. Vitamin D deficiency and insufficiency in pregnant women: a longitudinal study. Br J Nutr. 2009;102:876-81.

8. Bodnar LM, Catov JM, Simhan HN, Holick MF, Powers RW, Roberts JM. Maternal vitamin D deficiency increases the risk of preeclampsia. J Clin Endocrinol Metab. 2007;92(9):3517-22.

9. Shin JS, Choi MY, Longtine MS, Nelson DM. Vitamin D effects on pregnancy and the placenta. Placenta. 2010;31(12):1027-34

10. Lee JM, Smith JR, Philipp BL, Chen TC, Mathieu J, Holick MF. Vitamin D deficiency in a healthy group of mothers and newborn infants. Clin Pediatr (Phila). 2007;46:42-4.

11. Singla R, Gurung P, Aggarwal N, Dutta U, Kochhar R. Relationship between pre eclampsia and vitamin D deficiency: a case control study. Arch Gynecol Obstet. 2015;291(6):1247-51.

12. Ullah MI, Koch CA, Tamanna S, Rouf S, Shamsuddin L. Vitamin D deficiency and the risk of preeclampsia and eclampsia in Bangladesh. Horm Metab Res. 2013;45(9):682-7.

13. Abedi P, Mohaghegh Z, Afshary P, Latifi M. The relationship of serum vitamin $\mathrm{D}$ with pre-eclampsia 
in the Iranian women. Maternal Child Nutrition. 2014;10(2):206-12.

14. Bodnar LM, Simhan HN, Catov JM, Roberts JM, Platt RW, Diesel JC et al. Maternal Vitamin D status and the risk of mild and severe pre eclampsia. Epidemiology. 2014;25(2):207-14.

15. Robinson CJ, Alanis MC, Wagner CL, Hollis BW, Johnson DD. Am J Obstet Gynecol. 2010;203(4):366.e1-6.

16. Shand AW, Nassar N, Von Dadelszen P, Innis SM, Green TJ. Maternal vitamin D status in pregnancy and adverse pregnancy outcomes in a group at high risk for pre-eclampsia. BJOG. 2010;117(13):1593-8.

17. Powe CE, Seely EW, Rana S, Bhan I, Ecker J, Karumanchi SA et al. First trimester vitamin D, Vitamin D Binding protein, and subsequent preeclampsia. Hypertension. 2010;56(4):758-63.

18. Wetta LA, Biggio JR, Cliver S, Abramovici A, Barnes S, Tita AT. Is midtrimester vitamin D status associated with spontaneous preterm birth and preeclampsia? Am J Perinatol. 2014;31(6):541-6.
19. Tabesh M, Salehi-Abargouei A, Tabesh M, Esmaillzadeh A. Maternal vitamin D status and risk of pre-eclampsia: a systematic review and metaanalysis. J Clin Endocrinol Metab. 2013;98(8):316573.

20. Haugen M, Brantsaeter AL, Trogstad L, Alexander J, Roth C, Magnus P et al. vitamin D supplementation and reduced risk of pre eclampsia in nulliparous women. Epidemiology. 2009;20(5):720-6.

21. Marya RK, Rathee S, Monrow M. Effect of calcium and vitamin D supplementation on toxemia of pregnancy. Gynecol Obstet Invest. 1987;24:38-42.

22. Magnus P, Eskild A. Seasonal variation in the occurrence of pre-eclampsia. BJOG. 2001;108(11):1116-9.

23. Baker AM, Haeri S, Camargo CA Jr, Stuebe AM, Espinola JA. A nested case-control study of midgestation vitamin D deficiency and risk of severe preeclampsia. 2010;95(11):5105-9.

Cite this article as: Singh A, Mishra S, Aditya V, Srivastava R. Association of vitamin D deficiency with occurrence of pre eclampsia among inpatients of tertiary care centre, Gorakhpur, Uttar Pradesh, India. Int J Reprod Contracept Obstet Gynecol 2016;5:1304-8. 